\title{
A Doppler Radar and Conceptual Analysis of a Horizontal Longitudinal Vortex Influencing the Bastrop Complex Wildfire
}

\author{
GREGORY P. MURDOCH \\ National Weather Service, Midland, Texas \\ T. TODD LINDLEY \\ National Weather Service, Norman, Oklahoma \\ CHRISTOPHER J. MORRIS \\ National Weather Service, Amarillo, Texas
}

(Manuscript received 27 February 2016; review completed 23 June 2016)

\begin{abstract}
The Bastrop Complex wildfire (BCW) occurred during the record-breaking Texas drought of 2011. Although the $139.03 \mathrm{~km}^{-2}(34356 \mathrm{ac})$ fire burned an area much smaller than the state's largest wildfires, it was the largest wildland fire on record in central Texas, and the resultant property losses were unprecedented in Texas history. The $\mathrm{BCW}$ is of meteorological interest because of its simultaneous occurrence and interaction with a transient ambient horizontal longitudinal vortex (HLV). This study presents a conceptual review of HLVs from the perspectives of both meteorology and fire behavior. A thorough Doppler radar analysis of the BCW and its interaction with a transient pre-existing HLV is provided through observations of the remotely sensed debris plume. A basic conceptual model for the phasing of a wildland fire's circulation with an ambient HLV is presented, underscoring the advantages of using Doppler radar to diagnose near-fire environments for tactical firefighting applications.
\end{abstract}

\section{Introduction}

On 4 September 2011, the Bastrop Complex wildfire (BCW) ignited near Austin, Texas (Fig. 1), and became the most destructive wildland fire in recorded Texas history, destroying 1691 homes and killing two people (Jones et al. 2012). Strong winds associated with the dry, subsiding periphery of Tropical Storm Lee damaged power lines-igniting the BCW and other fires across central and eastern Texas. The BCW largely was in an area known as the Lost Pines with a thick understory (i.e., fuel model 9). Wildland fire history prior to the $\mathrm{BCW}$ was limited mostly to the Wildnerness Ridge Fire in 2009 in which 52 homes were lost and $6.03 \mathrm{~km}^{-2}$ (1491 ac) burned. Topographically, the Bastrop area is just east of the Hill Country escarpment and is characterized by rolling plains and is especially subject to the heat and dryness of the Texas summer fire season. The BCW occurred at the end of record drought and heat of 2011 and ignited on a day with high temperatures of $38^{\circ} \mathrm{C}\left(101^{\circ} \mathrm{F}\right)$, minimum relative humidity of $20 \%$, and wind gusts to 13.5 $\mathrm{m} \mathrm{s}^{-1}$ (30 mph) - burning an estimated $40.47 \mathrm{~km}^{-2}$ (10 $000 \mathrm{ac})$ on 4 September.

Localized variations in temperature, wind, humidity, and stability are the most dynamic meteorological factors that dictate wildland fire (Deeming et al. 1978; Heilman 1995), and changes in these variables within the near-fire environment can originate from meteorological features as innocuous as meso- $\gamma(2-20 \mathrm{~km}$, Orlanski 1975) surface-layer plumes (i.e., smoke) to more synoptically evident frontal passages. Influences of meso- $\beta$ (20-200 km) convective outflow boundaries on wind speed and direction historically have proven to be especially dangerous in the near-fire environment. Historic examples of such convective mesoscale influences resulting in firefighting tragedies include 


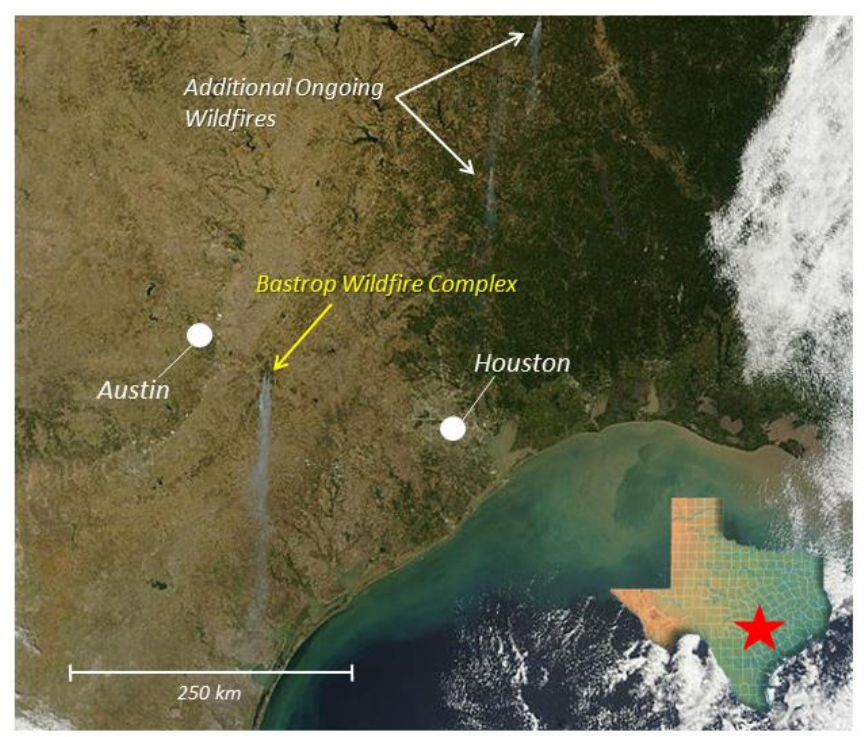

Figure 1. Regional visible satellite image over Texas showing the smoke plume from the BCW on 4 September 2011. Click image for an external version; this applies to all figures hereafter.

the 1990 Dude Fire (Goens and Andrews 1998) and the 2013 Yarnell Fire (Arizona State Fire Department 2013).

In addition to thunderstorms, other convective processes (ambient and fire-generated), such as lowlevel horizontally oriented vortices, have been shown to influence the character of wildland fire (Haines 1982; Forthofer and Goodrick 2011). In this study, the formation and evolution of fire-scale phasing of horizontal vortices is briefly reviewed, including the various descriptive terms of similar atmospheric vortices and their potential influence on wildland fire.

Section 2 reviews conceptual models in scientific literature for horizontal longitudinal vortices (HLVs), including common terminology describing horizontal rolls associated with both moist convection and wildland fire. In section 3, Weather Surveillance Radar1988 Doppler (WSR-88D, Crum and Alberty 1993) reflectivity data from 4 September 2011 are analyzed and used to identify a horizontal vortex in proximity to the BCW. Based on these observations, subsequent sections propose the use of meteorological radar in monitoring the near-fire environment in tactical decision support forecasting for firefighting, as well as offering evidence that supports the role of HLVs in crown fire behavior.

\section{Conceptual model of low-level horizontal vortices}

Horizontally oriented low-level vortices occur frequently in the atmosphere and have been the topic of extensive studies, including those by Brown (1980) and Etling and Brown (1993). Mal (1930) was among the first to observe that alternating bands of rising air result in parallel cloud streets. Later work by Keuttner $(1959,1971)$ concluded that not only are cloud streets that occur on various scales common, but they occur at all latitudes and in some areas they represent the most prominent form of convection. This supported evidence by Bagnold (1952) and Hanna (1969) that suggested long parallel systems of sand dunes found in more than half of Earth's deserts are in fact aligned and spaced by this atmospheric mechanism.

Forthofer and Goodrick (2011) summarized the process in which low-level horizontally oriented vortices form. They described that in the absence of wind, warm air near the ground begins to rise in the form of circulation cells, a process known as Rayleigh-Bernard convection (Fernando and Smith 2001). When these cells are subjected to wind shear, they become more organized, and common fair-weather cumulus clouds mark the top of cell updrafts. As wind shear increases, the convective cells organize into horizontal convective rolls that are perpendicular to the mean wind; however, further increases in vertical wind shear alter the balance between buoyancy-driven vorticity and shear-driven vorticity. This results in the convective rolls becoming oriented parallel to the mean wind (Fig. 2, Keuttner 1971). Shear, independent of convection, also is a horizontal vorticity source, and streamwise horizontal vorticity in boundary layer flow can grow its energy exponentially over the initial state (K. M. Butler 2015, personal communication). Another analogous type of flow is when boundary layer flow over a curved surface forms what is known as Gortler vortices (Saric 1994).

Horizontal vortices have been recognized as circulations that can augment deep moist convection when in alignment with the sea breeze front (Dailey and Fovell 1999). Also, daytime heating may enhance the updraft segment of a horizontal vortex, providing the additional lift needed for thunderstorm initiation (Edwards et al. 2000). Furthermore, when deep moist convection ingests horizontal vorticity, the character of convection can morph into a balance between shear and buoyancy-resulting in long-lived, dangerous storms. In agreement with the foundational research of Davies-Jones (1984), Forthofer and Goodrick (2011) found that horizontal vortices have the potential to augment fires.

A literature review of work on low-level horizontal vortices reveals the use of inconsistent terminology 


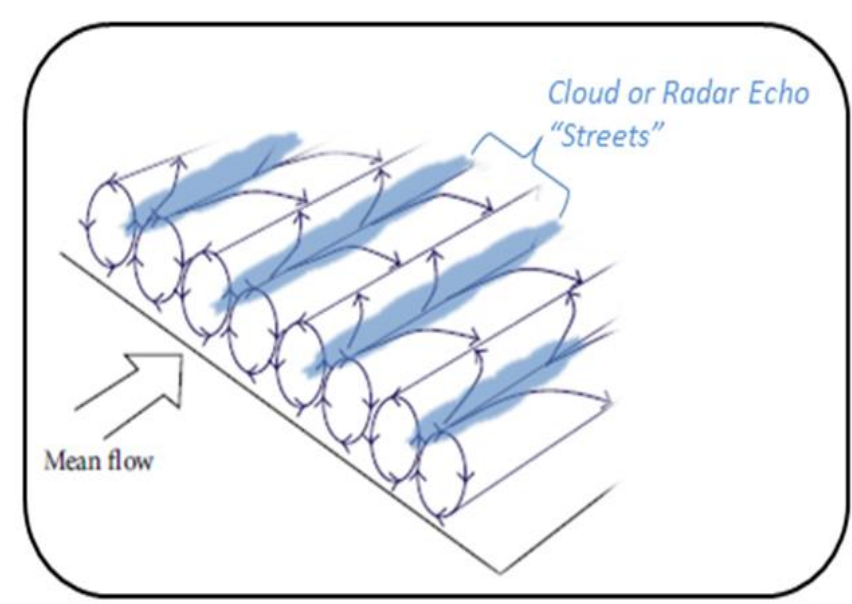

Figure 2. An illustration of a conceptual model of low-level horizontal vortices parallel to the mean flow.

among meteorological sub-specialties. Traditionally, meteorologists concerned with the influences of thermal-kinematic circulations within the planetary boundary layer (PBL) on deep moist convection have used descriptors such as horizontal convective rolls (HCRs, Edwards et al. 2000), vortex lines (DaviesJones 1984), and horizontal vorticity (Doswell 2016). These terms were then referenced with respect to the vertical wind shear and storm-relative wind as either streamwise or crosswise vorticity. In contrast, works that have applied similar conceptual models to wildland fire have referred to the phenomenon as either vertical or horizontal vorticity, and have referenced the component relative to the orientation of vertical wind shear vectors as either longitudinal or transverse. This convention has been most recently championed by Forthofer and Goodrick (2011) in their comprehensive review of vortices associated with wildland fire. Haines (1982) referred to the phenomenon as horizontal roll vortices (HRVs) and the Glossary of Meteorology (Glickman 2000) defines both HCRs and HRVs as acceptable terms for the spectrum of thermal-kinematic-driven horizontal circulations within the PBL.

\section{BCW radar observations and analysis}

Because the WSR-88D can detect cold fronts and outflow boundaries, it can be used to provide advanced warning of atmospheric features that influence changes in fire behavior. WSR-88Ds have been utilized in past studies to identify low-level horizontal vortices (Weckwerth et al. 1996; Edwards et al. 2000), and these features typically are identified on radar as long and narrow returns with low reflectivity values (0-20 $\mathrm{dBZ}$ ). In observational roll vortex studies and in mi- gratory biological studies the low reflectivity values have been identified as biological scatters, insects, and predatory birds caught in the circulatory branches of the updrafts and downdrafts (Weckwerth et al. 1996). These horizontal vortices may be quasi-stationary or moving along with the general steering flow. The conceptual model for ambient horizontal vortices is counter-rotating pairs such that the upward/downward motion couplets are aligned (Fig. 2) with aspect ratios of 2.2-6.5 (Weckwerth et al. 1997). Figure 3 shows adjacent counter-rotating circulations and calculations using the Granger, Texas (KGRK), WSR-88D; a proximity sounding from Fort Worth and Corpus Christi produced an aspect ratio of five for the $\mathrm{BCW}$ case. Because of the lack of mesoscale surface boundaries on 4 September, there is further inference in the WSR$88 \mathrm{D}$ reflectivity data of a series of well-developed horizontal vortices (Fig. 4a). The ambient horizontal vortices seen in the $\mathrm{BCW}$ case are parallel to the mean surface-3-km mean sea level (MSL) wind shear vector (thick red arrow in Fig. 4b), and therefore are of the longitudinal type.

\section{a. Radar analysis of the debris plume}

A WSR-88D-detected fire is a measure of the debris plume, and its reflectivity gets larger when heat flux increases combustion and the resultant buoyant force lofts large burnt debris (Jones and Christopher 2009). Between 2255 and 2329 UTC, the ambient HLV approached, then phased with the left flank of the fire, and was absorbed into the debris plume. Figure 5 documents the debris plume's response to the ambient HLV. At 2306 UTC, the ambient HLV phased with the left flank of the BCW and reflectivity within the debris plume increased from $34.5 \mathrm{dBZ}$ at 2306 UTC to $48 \mathrm{dBZ}$ at $2312 \mathrm{UTC}$ (Fig. 5). In the subsequent $6 \mathrm{~min}$, the debris plume's height (Fig. 5, blue line) increased from $4.8 \mathrm{~km}(15.7 \mathrm{kft})$ to $5.2 \mathrm{~km}(17.1$ $\mathrm{kft})$. By 2329 UTC, the HLV was absorbed into the debris plume and became unidentifiable as the debris plume waned to $36 \mathrm{dBZ}$ from the 2312 UTC maximum.

\section{b. An explanation of strengthened debris plume in as- sociation with an $H L V$}

Haines (1982) pointed out that for an eastwardmoving (southward-moving) fire, a left flank or north side (east side) counter-clockwise circulation produces a fire-induced vortex. It is the alignment, or phasing, of the fire's convectively driven circulation and the 


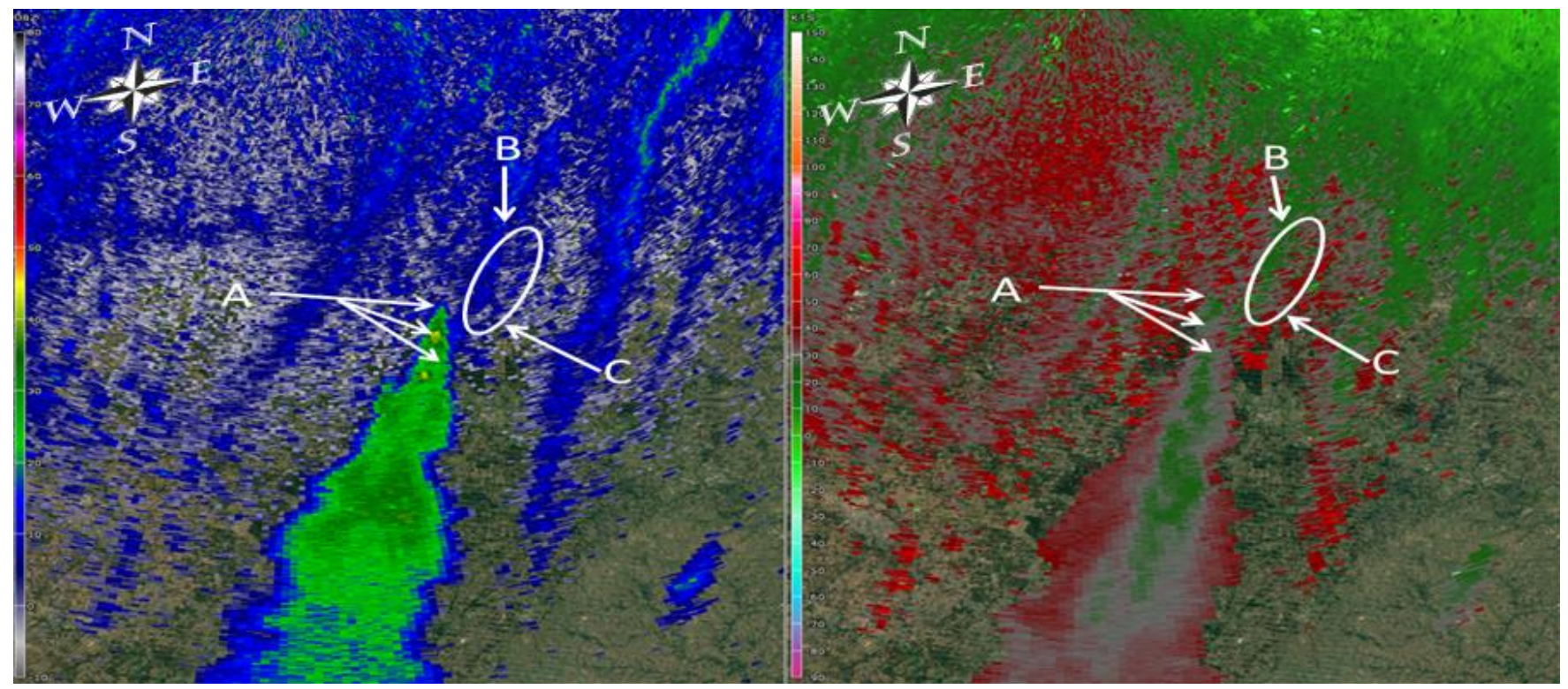

Figure 3. Images of the $0.5^{\circ}$ reflectivity (left) and storm-relative velocity (right) from the KGRK WSR-88D at 2312 UTC 4 September. The A, B, and C markers are over the same locations on both images. In the right image, A points to a series of convergent-divergent couplets within the debris plume; B denotes the HLV approaching the debris plume from the north, and C denotes the divergent portion of the HLV circulation.

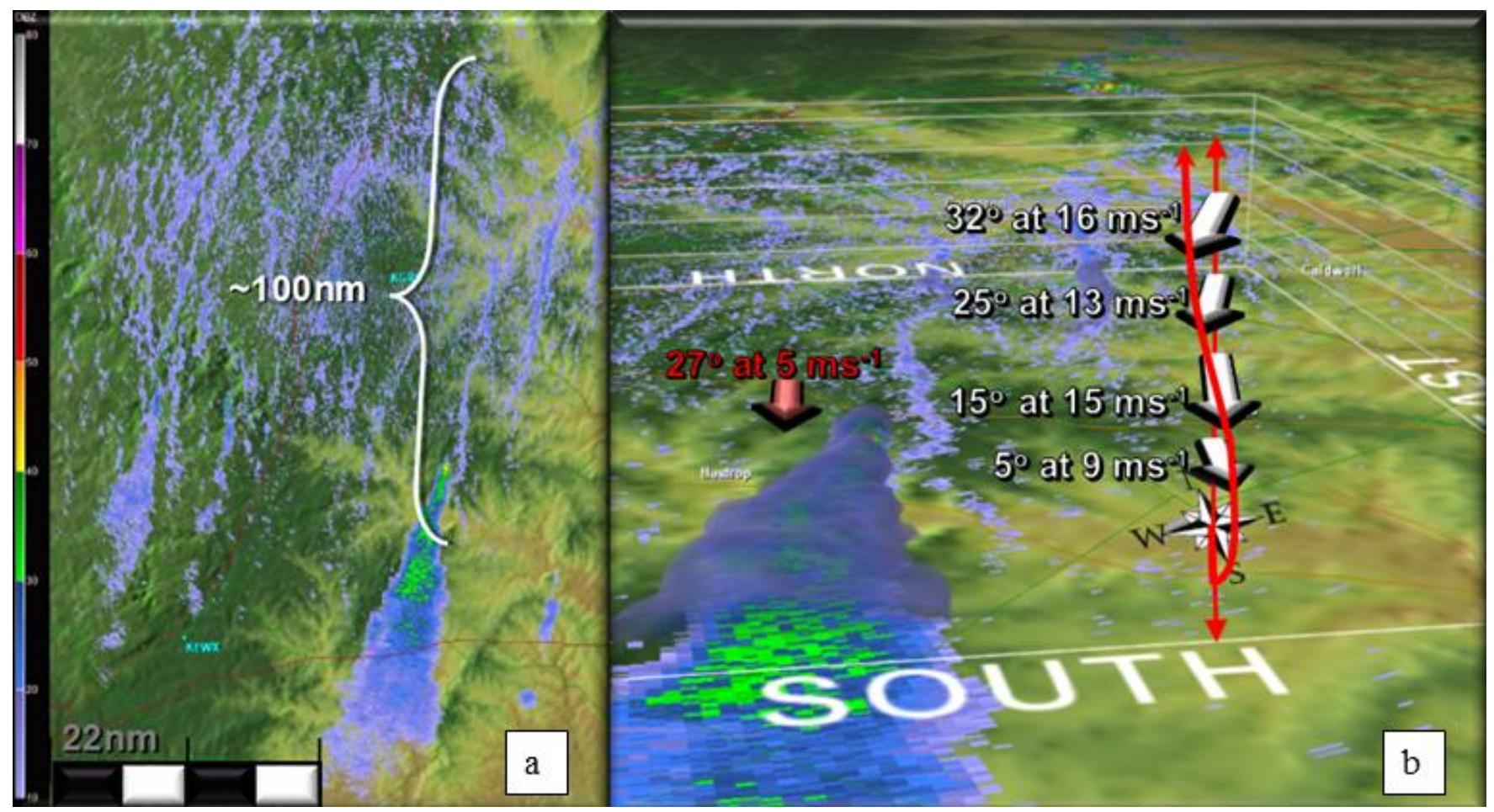

Figure 4. (a) Horizontal scale of HLVs at 2312 UTC 4 September from KGRK reflectivity data. (b) Volumetric display of reflectivity showing a distinct HLV on the left flank (east side) with an overlay of a proximity vertical wind profile from the Dallas/Fort Worth, TX (KFWD), sounding at 0000 UTC 5 September-showing the mean surface-3-km MSL wind shear vector.

ambient HLV that is considered as a means of augmenting the debris plume of the BCW between 2306 and 2329 UTC. Using radar to measure the radial distances of the fire-induced vortex and the HLV shows a comparable scale of $1 \mathrm{~km}$ and $1.1 \mathrm{~km}$, respectively. Figure 6 is a basic conceptualization of the fire's flank circulation and the HLV circulation, revealing phased descending branches (vertical transport of thermal en- 


\section{Time series of reflectivity versus height (KGRK WSR-88D)}

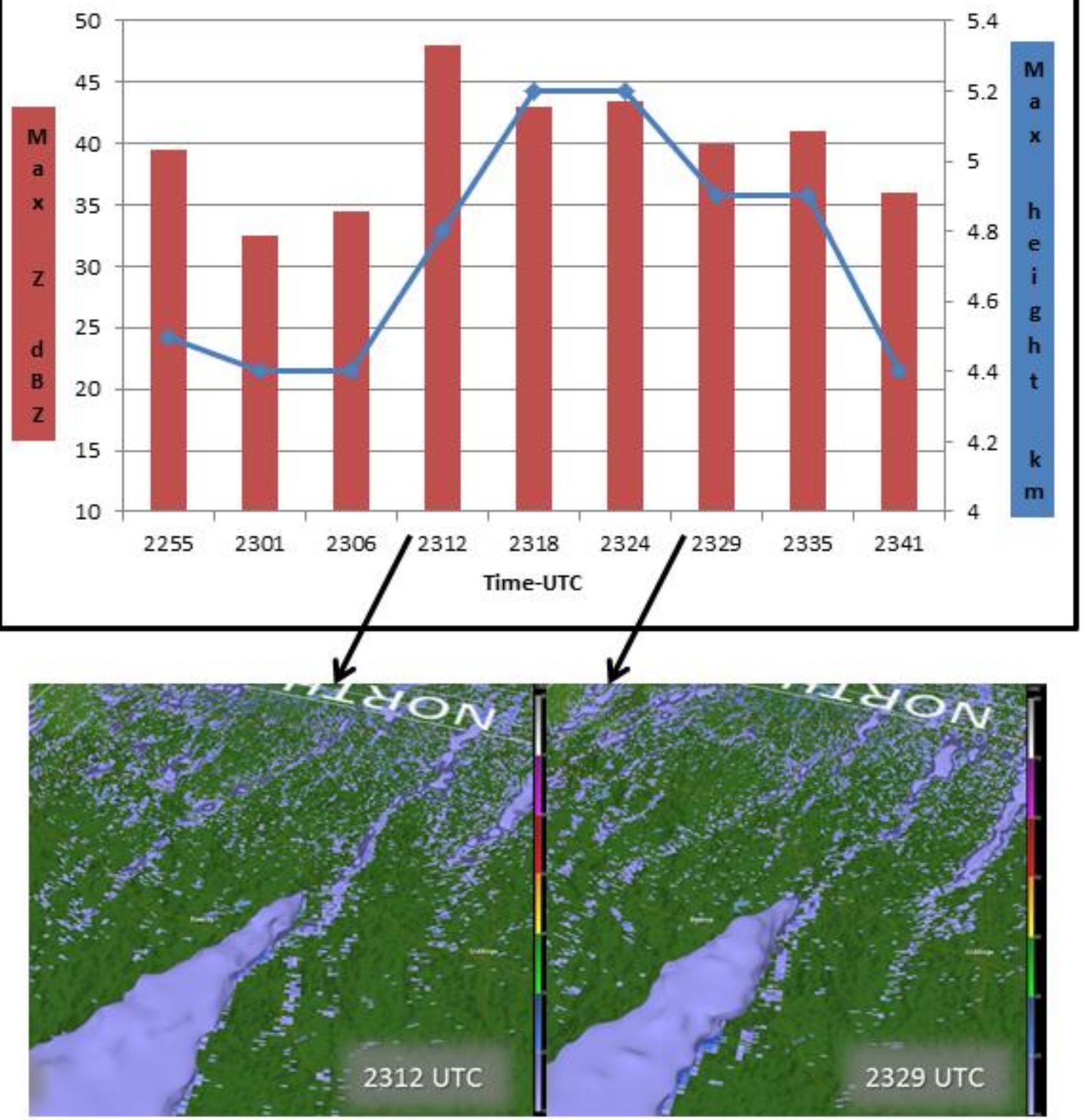

Figure 5. (top) Time series of maximum reflectivity (dBZ) and vertical height (km) of the debris plume. (bottom) Time-relevant insets (per black arrows) of associated volumetric displays and $0.5^{\circ}$ reflectivity (dBZ).

ergy and momentum transfer) - a mechanism resulting in enhanced local subsidence east of the left flank. The subsidence (overlapping red and white arrows in Fig. 6) may augment the dry and warm wind on the flank, serving to increase combustion, and thus buoyancy and lofting of embers in the debris plume.

\section{Tactical applications}

Meteorologists maintain an awareness of changes in the near-storm environment so the evolution of storm-scale characteristics and behavior can be anticipated. An analogous method is valid for the near-fire environment with respect to wildland fire's interaction with atmospheric features. Fires also have "near-fire environments" with respect to fuel, topography, and weather. These environmental factors generally are considered to be "known" and changes in these characteristics are incorporated into tactical firefighting. The authors acknowledge that in many instances the changes in a fire's debris plume may additionally oc- 


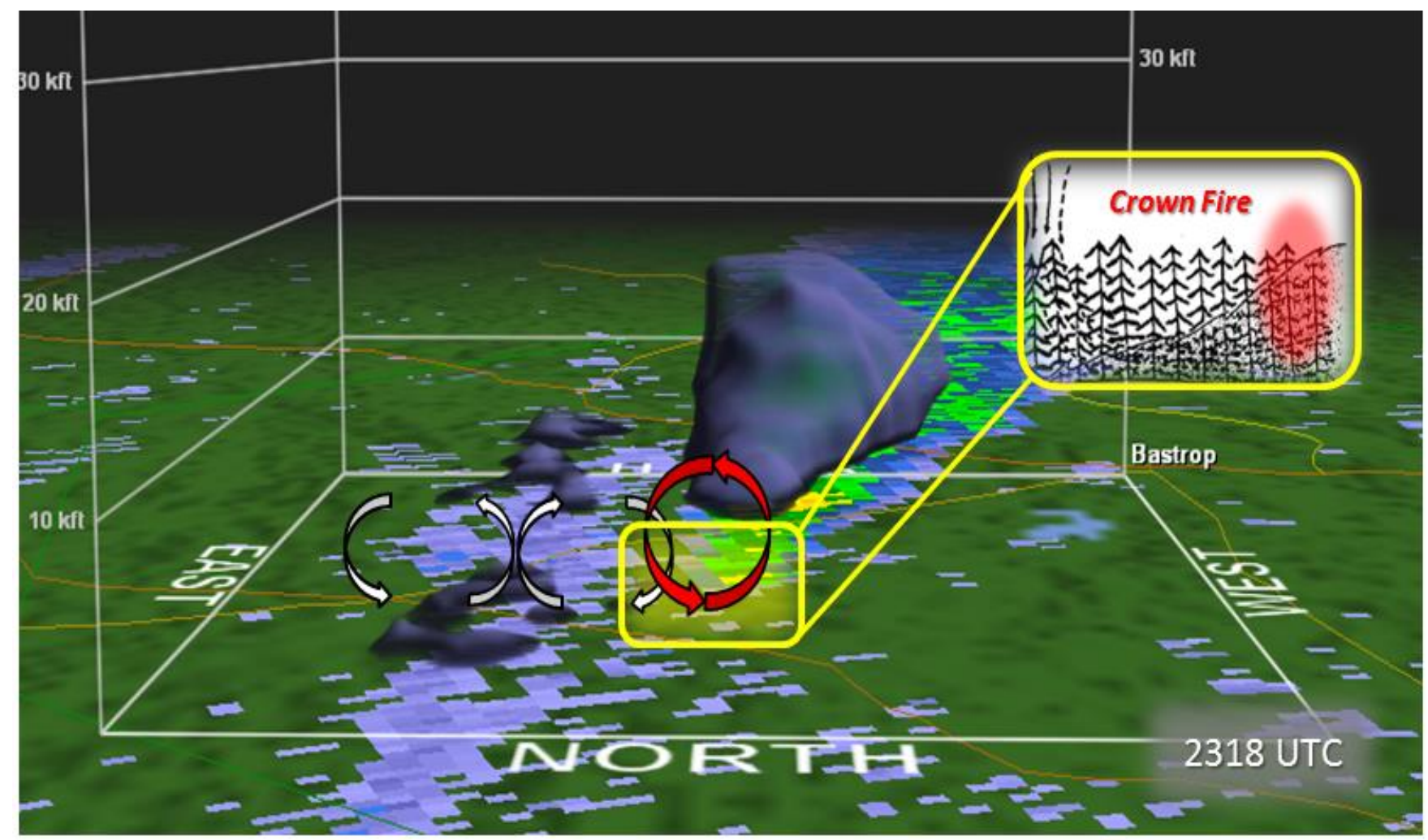

Figure 6. Phasing of the descending branches may enhance warm and dry flank winds and, thus, potentially increase combustion on the flank.

cur as a result of changes in either the fuel or topography environments, but such changes also may be important indicators of changes in fire behavior resulting from meteorological influences.

The identification of HLVs, and their potential to impact a fire's debris plume, is emphasized with respect to short-term bursts in spotting and lateral flank advances. In the BCW, the presence of the HLV coincided with increased reflectivity of the radar-detected debris plume and increased heights of lofted embers. Because larger (and presumably, a higher volume of) embers were lofted higher into the atmosphere, it follows that there was an associated increased risk of new ignitions farther downstream. This process is known as "spotting." The post-fire investigation of the BCW revealed spotting indeed initiated a number of new fires. Although a quantitative measure of increased spotting with respect to the HLV is not provided here, the HLV's potential to augment combustion leading to increased buoyancy and greater spotting distances and new ignitions provides a framework for improved tactical firefighting operations. Cheney and Bary (1969) observed that most spotting on wildfires occurred within a "fan-shaped" zone of $9^{\circ}$ either side of the "primary wind." Application of the WSR-88D-gener- ated vertical wind profile and the azimuthal data within the radar-identified debris plume-along with the forecast spotting distances - allows for a strategic positioning of fire crews in space and time. It is the recognition of an HLV within the near-fire environment that may alter these typical spotting tendencies and allow for proactive positioning of fire crews.

Emphasis around the HLV has been with respect to the vertical circulation; however, there is observational evidence in other studies that shows surface winds vary in direction near horizontal convection. Edwards et al. (2000) noted a wind change from southsoutheast to south-southwest in the mesonet data coincident with radar-observed horizontal convection. A loop of radar data in the BCW case indicates the ambient HLV oscillated transversely to the mean flow as it moved south. In general, fire-line observations indicate that there are short temporal wind shifts, known as "quartering winds", in which grassland fuels can result in lateral flank advances. An HLV is a result of convective and shear processes by which changes in wind direction occur, and thus a mechanism that increases combustion through lateral flank surges and debris plumes with increased reflectivity. 


\section{Post-fire evidence of crown fire and crown streets}

Wildland crown fires advance from top-to-top of trees and shrubs - at times independent of the surface fire - and are very dangerous natural phenomena (Van Wagner 1977; Werth et al. 2011). Haines (1982) provided observational evidence from analyses of nine crown fires that suggests low-level horizontal vortices are a major mechanism that contribute to the induction of crown fires. Haines' study hypothesized that although strong downward motion of air along the parallel cloudless streets of horizontal vortices initially suppresses crown fires within the zone of strongest subsidence, these downdrafts enhance entrainment of dry, warm air and intensify lateral spread. Fire is then forced outward and toward the vegetative fuel canopy along the vortex periphery as air begins to ascend (Fig. 7). Supporting visual evidence was presented by postfire aerial photography, which showed parallel burn streets following the 1980 Mack Lake Fire (Fig. 8a, Simard et al. 1982). Haines concluded that such burn street char patterns are in no sense localized or unique, and they represent evidence of low-level horizontal rolls that are a primary mechanism for the induction of a crown fire.

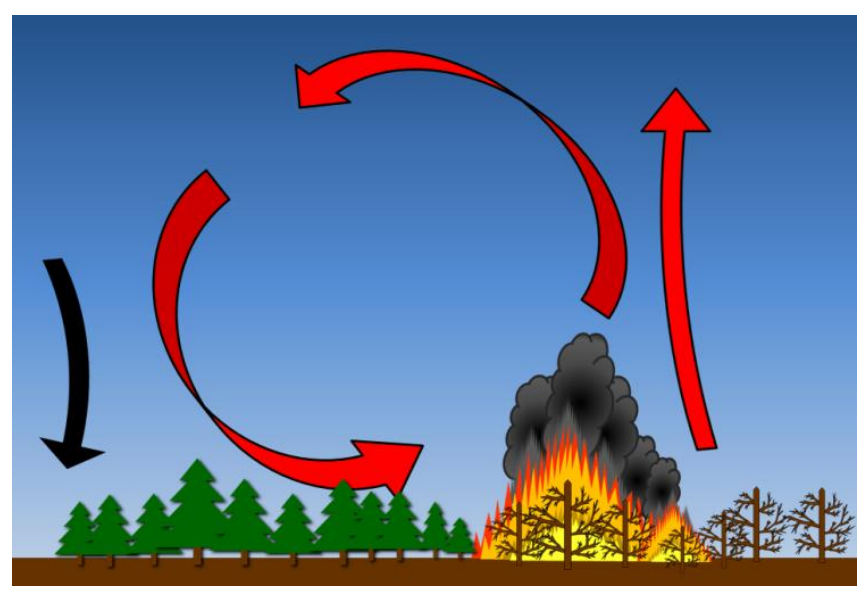

Figure 7. Conceptual model of a horizontal roll vortex in a crown fire (modified from Haines 1982). Red arrows represent fire-induced horizontal roll. Black arrow represents general ambient circulation.

Crown street char patterns similar to those presented by Haines (1982) and Simard et al. (1982) were observed within the BCW burn scar (Fig. 8b). In fact, post-fire imaging from the NASA Earth Observing Systems Landsat 5 Thematic Mapper (Fig. 8c) was used to identify areas of varying burn intensity within the $\mathrm{BCW}$. The data reveal parallel street patterns of "high severity burn." Pine trees within the BCW were
21-27 m (70-90 ft) and spacing between streets was observed to be approximately $90 \mathrm{~m}(300 \mathrm{ft})$, wider for the less-defined edges. This generally compares well with other unrelated observed crown street spacing of 1-3 times the tree heights. These observations, along with a post-fire analysis, are significant because they provide confirmation that a crown fire and crown fire streets occurred (R. Gray 2016, personal communication). Furthermore, in comparison to Haines' (1982) nine-case crown fire study, the observed weather during the BCW falls within the study's domain. The average wind speed for the BCW from nearby observations indicate a $4-6 \mathrm{~m} \mathrm{~s}^{-1}(10-14 \mathrm{mph})$ sustained wind, while the average wind for Haines' crown fire cases was $5.4 \mathrm{~m} \mathrm{~s}^{-1}(12 \mathrm{mph})$. The exception is the Dudley Fire which was much stronger at $13-22 \mathrm{~m} \mathrm{~s}^{-1}$ (29-49 mph).

Conclusions here are not formulated such that the ambient HLV observed by the WSR-88D had a direct influence on the initiation or intensification of the crown fire or the crown street pattern on the BCW. However, there are two observations made in the $\mathrm{BCW}$ radar and photographic data that are appropriate for consideration with respect to Haines' (1982) scenarios for HLV development related to crown streets and Forthofer and Goodrick's (2011) concern for lateral advances. Haines (1982) states his third scenario as follows:

A third possibility would utilize atmospheric vortices of various scales, the type that occur in any natural boundary-layer flow. These vortices are enhanced by heating of the boundary layer from below, and the observed tree crown streets and char pattern result. Problem: The scales of these natural vortices would have to fit the perimeter, perhaps too conveniently.

At 2318 and 2319 UTC the WSR-88Ds at KGRK and San Antonio, Texas (KEWX), respectively, show that the HLV natural vortices did temporarily fit the debris plume perimeter (Fig. 9). This is an important observation because it is the first documented case in Texas of HLVs fitting the debris plume perimeter. The implications with respect to crown fires or crown streets are unknown, but confirm that a fire's circulation and that of an ambient HLV can come into alignment.

Following the debris plume's ingestion of the HLV, there was a noted lateral bulge of the debris plume on the left flank (Fig. 10). The conclusion of 


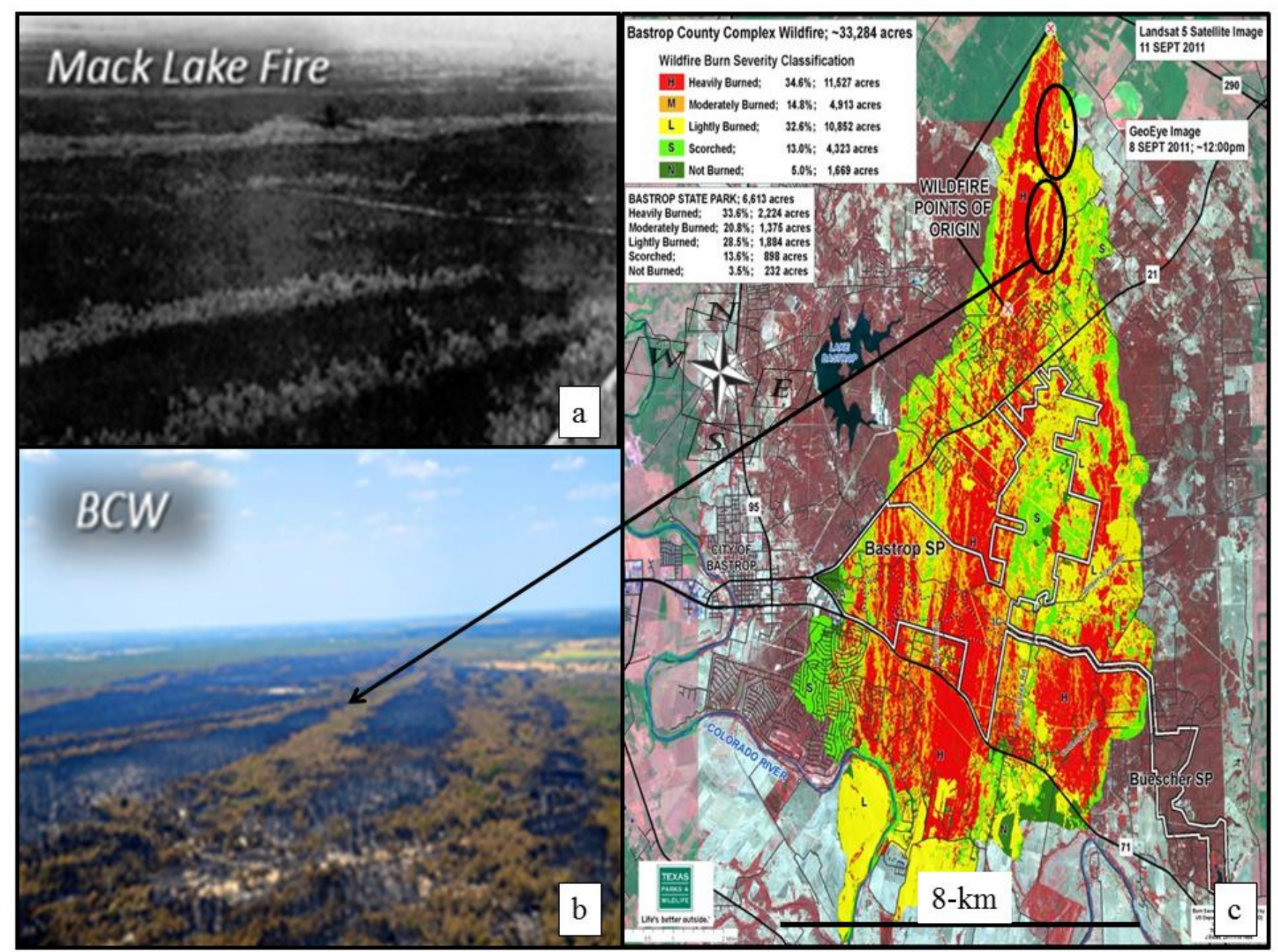

Figure 8. Evidentiary photographs of a crown fire seen in crown streets on the Mack Lake fire (a) and BCW (b and c). The black arrow from the oval in (c) points to the photograph of same area in (b), and the second black oval to the north shows another area of crown streets.

this radar and photographic evidence as it relates to lateral surges is indefinite, but corroborates Forthofer and Goodrick's (2011) concern about the potential for lateral surges.

\section{Conclusion}

Multiple HLVs were identified through applying conceptual models of low-level horizontal vortices to WSR-88D data. One HLV moved adjacent to, and phased with, the left flank of the BCW between 2312 and 2329 UTC. This phasing was concurrent with increased reflectivity within the radar-detected debris plume from 34.5 to $48 \mathrm{dBZ}$. A conceptual model for the phased descending branches of an ambient atmospheric HLV and the left-flank, fire-induced vortex was introduced. The conceptual model emphasizes the potential for increased subsidence caused by the phased descending branches that increase warm and dry conditions on the flank. This results in increased buoyancy through combustion and increased reflectivity within the radar-detected debris plume. Tactical applications were suggested that include awareness of the near-fire environment and the potential for HLVs to increase the likelihood of spotting with increased rates of spread and wind shifts impacting lateral spread. Visual evidence of crown streets were confirmed through post-fire photographs, and a perimeter-conforming HLV was observed in the radar data-supporting an early research hypothesis of horizontal convection and crown fire interaction. Lateral bulges also were confirmed in radar data after ingestion of the HLV into the debris plume.

Acknowledgments. The authors thank Eric Platt (WFO EWX) for the initial gathering of the radar data and John 


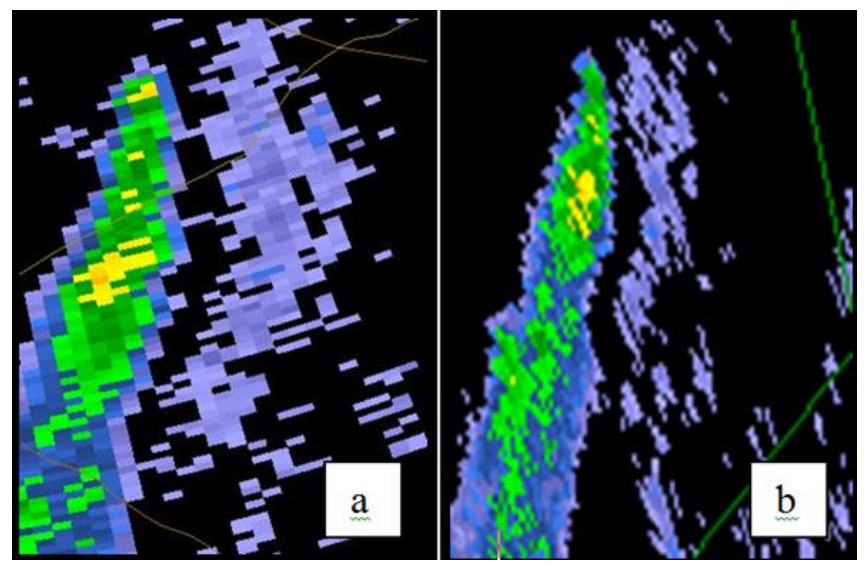

Figure 9. $0.5^{\circ}$ reflectivity for (a) KGRK at 2318 UTC and (b) KEWX at 2319 UTC showing the ambient HLV conforming to the shape of the debris plume.

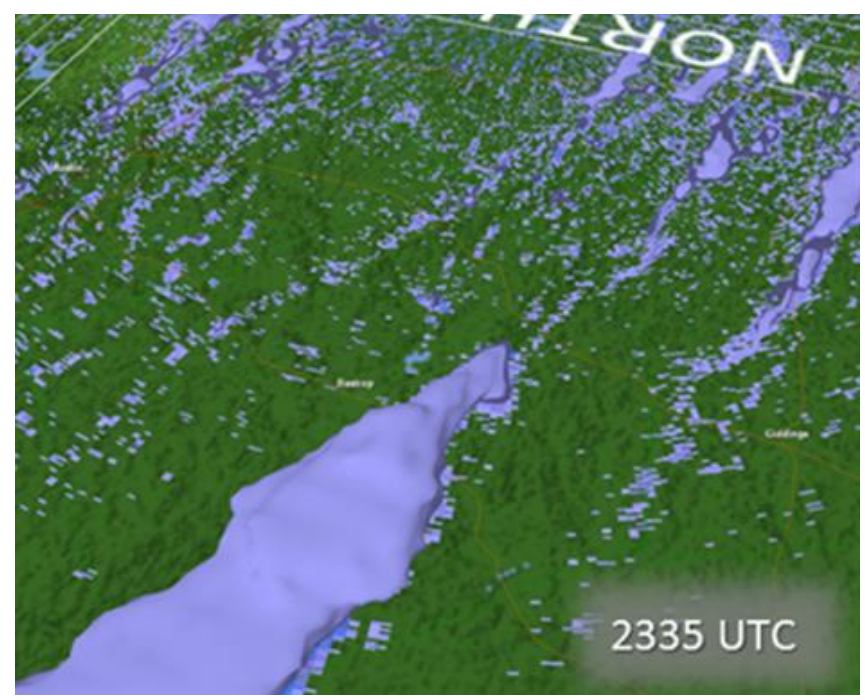

Figure 10. Radar evidence of a left-flank lateral bulge after ingestion of the HLV into the debris plume.

Cockrell (WFO AMA), Brian Curran (WFO Midland), and Jon Zeitler and Monte Oaks (WFO EWX) for their reviews. In addition, the authors thank Vivek Mahale (WFO OUN) and Andrew Arnold (WFO Midland) for help with graphics, Rich Gray and Brad Smith (Texas A\&M Forest Service) for fire-specific information, and Bastrop County for permission to use the photograph in Fig. 8 b.

\section{REFERENCES}

Arizona State Fire Department, 2013: Yarnell Hill fire: Serious accident investigation report. International Association of Wildland Fire, 25 pp. [Available online at www.iawfonline.org/Yarnell_Hill_Fire_report.pdf.]

Bagnold, R. A., 1952: The surface movement of blown sand in relation to meteorology. Proceedings of the
International Symposium on Desert Research, Research Council of Israel, Jerusalem, 1-6.

Brown, R. A., 1980: Longitudinal instabilities and secondary flows in the planetary boundary layer: A review. Rev. Geophys., 18, 683-697, Crossref.

Cheney, N. P., and G. A. V. Bary, 1969: The propagation of mass conflagrations in a standing eucalypt forest by the spotting process. In Mass Fire Symposium, Defense Standards Laboratory, Canberra, Australia, 10-12.

Crum, T. D., and R. L. Alberty, 1993: The WSR-88D and the WSR-88D Operational Support Facility. Bull. Amer. Meteor. Soc., 74, 1669-1687, Crossref.

Dailey, P. S., and R. G. Fovell, 1999: Numerical simulation of the interaction between the sea-breeze front and horizontal convective rolls. Part I: Offshore ambient flow. Mon. Wea. Rev., 127, 858-878, Crossref.

Davies-Jones, R., 1984: Streamwise vorticity: The origin of updraft rotation in supercell storms. J. Atmos. Sci., 41, 2991-3006, Crossref.

Deeming, J. E., R. E. Burgan, and J. D. Cohen, 1978: The National Fire Danger Rating System-1978. General Technical Report INT-39, USDA Forest Service, Intermountain Research Station, Ogden, Utah, 63 pp.

Doswell, C. A., III, cited 2016: A primer on vorticity for application in supercells and tornadoes. [Available online at www.flame.org/ cdoswell/vorticity/vorticity primer.html.]

Edwards, R., R. L. Thompson, and J. G. LaDue, 2000: Initiation of storm A (3 May 1999) along a possible horizontal convective roll. Preprints, 20th Conf. on Severe Local Storms, Orlando, FL, Amer. Meteor. Soc., 60-63. [Available online at www.spc.noaa.gov/ publications/edwards/hcr3may.htm.]

Etling, D., and R. A. Brown, 1993: Roll vortices in the planetary boundary layer: A review. Bound.-Layer Meteor., 65, 215-248, Crossref.

Fernando, H. J. S., and D. C. Smith IV, 2001: Vortex structures in geophysical convection. Eur. J. Mech. B-Fluid, 20, 437-470, Crossref.

Forthofer, J. M., and S. L. Goodrick, 2011: Review of vortices in wildland fire. J. Combust., 2011, 1-14, Crossref.

Glickman, T. S., Ed., 2000: Glossary of Meteorology. 2nd ed. Amer. Meteor. Soc., 855 pp.

Goens, D. W., and P. L. Andrews, 1998: Weather and fire behavior factors related to the 1990 Dude Fire near Payson, Arizona. Preprints, Second Symposium on Fire and Forest Meteorology, Boston, MA, Amer. Meteor. Soc., 153-158. [Available online at www.fireleader ship.gov/toolbox/staffride/downloads/lsr11/lsr11_relate d_factors.pdf.]

Haines, D. A., 1982: Horizontal roll vortices and crown fires. J. Appl. Meteor., 21, 751-763, Crossref.

Hanna, S. R., 1969: The formation of longitudinal sand dunes by large helical eddies in the atmosphere. J. Appl. Meteor., 8, 874-883, Crossref. 
Heilman, W. E., 1995: Synoptic circulation and temperature patterns during severe wildland fires. Preprints, Ninth Conf. on Applied Climatology. Dallas, TX, Amer. Meteor. Soc., 346-351.

Jones, J., A. Saginor, and B. Smith, 2012: 2011 Texas wildfire common denominators of home destruction. Texas A\&M Forest Service, 52 pp. [Available online at texasforestservice.tamu.edu/uploadedFiles/TFSMain/Pr eparing_for_Wildfires/Prepare_Your_Home_for_Wildf ires/Contact Us/2011\%20Texas\%20Wildfires.pdf.]

Jones, T. A., and S. A. Christopher, 2009: Injection heights of biomass burning debris estimated from WSR-88D radar observations. IEEE Trans. Geosci. Remote Sens., 47, 2599-2605, Crossref.

Keuttner, J., 1959: The band structure of the atmosphere. Tellus, 11, 267-294, Crossref.

, 1971: Cloud bands in the earth's atmosphere: Observations and theory. Tellus, 23, 404-426, Crossref.

Mal, S., 1930: Forms of stratified clouds. Beitr. Phys. Atmos., 18, 40-70.

Orlanski, I., 1975: A rational subdivision of scales for atmospheric processes. Bull. Amer. Meteor. Soc., 56, 527-530.
Saric, W. S., 1994: Görtler vortices. Annu. Rev. Fluid Mech., 26, 379-409, Crossref.

Simard, A. J., D. A. Haines, J. S. Frost, and R. W. Blank, 1982: The Mack Lake Fire. USDA Forest Service, North Central Forest Experiment Station Research, 40 pp. [Available online at www.nrs.fs.fed.us/pubs/gtr/ gtr_nc083.pdf.]

Van Wagner, C. E., 1977: Conditions for the start and spread of crown fire. Can. J. For. Res., 7, 23-24, Crossref.

Weckwerth, T. M., J. W. Wilson, and R. M. Wakimoto, 1996: Thermodynamic variability within the convective boundary layer due to horizontal convective rolls. Mon. Wea. Rev., 124, 769-784, Crossref.

, and N. A. Crook, 1997: Horizontal convective rolls: Determining the environmental conditions supporting their existence and characteristics. Mon. Wea. Rev., 125, 505-526, Crossref.

Werth, P. A., and Coauthors, 2011: National Wildfire Coordinating Group: Synthesis of knowledge of extreme fire behavior: Volume 1 for fire managers. PNW-GTR-854, USDA Forest Service, Pacific Northwest Research Station, Portland, Oregon, 107135. 